\title{
Comparison of Natural Course between Thyroid Cancer Nodules and Thyroid Benign Nodules
}

\author{
Kyun-Jin Yun ${ }^{1, *}$, Jeonghoon $\mathrm{Ha}^{2}{ }^{2}$, Min-Hee Kim², Ye Young Seo ${ }^{3}$, Mee Kyoung Kim¹ ${ }^{1}$ Hyuk-Sang Kwon ${ }^{1}$, \\ Ki-Ho Song ${ }^{1}$, Moo Il Kang ${ }^{2}$, Ki-Hyun Baek ${ }^{1}$ \\ ${ }^{1}$ Division of Endocrinology and Metabolism, Department of Internal Medicine, Yeouido St. Mary's Hospital, College of \\ Medicine, The Catholic University of Korea; ${ }^{2}$ Division of Endocrinology and Metabolism, Department of Internal Medicine, \\ Seoul St. Mary's Hospital, College of Medicine, The Catholic University of Korea; ${ }^{3}$ Department of Nuclear Medicine, Inje \\ University Sanggye Paik Hospital, Inje University College of Medicine, Seoul, Korea
}

Background: The natural course of thyroid cancer nodules and benign nodules is different. This study was to compare the changes in size between thyroid cancer nodules and thyroid benign nodules. The risk factors associated with the changes of thyroid cancer nodules were assessed.

Methods: This study contains retrospective observational and prospective analysis. A total of 113 patients with 120 nodules were recruited in the cancer group, and 116 patients with 119 nodules were enrolled in the benign group. Thyroid ultrasonography was performed at least two times at more than 1-year interval.

Results: The mean follow-up durations were 29.5 \pm 18.8 months (cancer group) and 31.9 \pm 15.8 months (benign group) $(P=0.32)$. The maximum diameter change in length was $0.36 \pm 0.97 \mathrm{~mm} /$ year in the cancer group and $-0.04 \pm 0.77 \mathrm{~mm} /$ year in the benign group $(P<0.01)$. The volume was significantly increased in the cancer group compared with the benign group $(0.06 \pm 0.18 \mathrm{~mL} / \mathrm{year}$ vs. $0.004 \pm 0.05 \mathrm{~mL} /$ year, respectively, $P<0.01 ; 26.9 \% \pm 57.9 \% /$ year vs. $1.7 \% \pm 26.0 \% /$ year, $P<0.01)$. Initial maximum diameter $(\beta=0.02, P<0.01)$ and initial volume $(\beta=0.13, P<0.01)$ were significantly associated with volume change $(\mathrm{mL}) /$ year. Initial maximum standardized uptake value did not predict the nodule growth.

Conclusion: It is suggested that thyroid cancer nodules progress rapidly compared with benign nodules. Initial size and volume of nodule were independent risk factors for cancer nodule growth.

Keywords: Thyroid nodule; Thyroid neoplasms; Biopsy, fine-needle; Tumor burden

\section{INTRODUCTION}

Thyroid cancer is the most common cancer in South Korean women [1]. It is an indolent disease with a low mortality rate. Additionally, several published autopsy studies have reported

Received: 19 February 2019, Revised: 2 May 2019, Accepted: 10 May 2019 Corresponding author: Ki-Hyun Baek

Division of Endocrinology and Metabolism, Department of Internal Medicine, Yeouido St. Mary's Hospital, College of Medicine, The Catholic University of Korea, 10 63-ro, Yeongdeungpo-gu, Seoul 07345, Korea

Tel: +82-2-3779-1400, Fax: +82-2-780-3132, E-mail: drbkh@catholic.ac.kr that the small occult thyroid cancer can be detected with a high degree of probability [2-4]. Small thyroid cancer without highrisk factors does not have any symptoms and affect survival rate. However, surgery is considered the optimal treatment for thyroid cancer immediately after diagnosis. Therefore, its natu-

\section{Copyright () 2019 Korean Endocrine Society}

This is an Open Access article distributed under the terms of the Creative Commons Attribution Non-Commercial License (http://creativecommons.org/ licenses/by-nc/4.0/) which permits unrestricted non-commercial use, distribution, and reproduction in any medium, provided the original work is properly cited.

*These authors contributed equally to this work. 
ral course remains unclear. Only a small number of thyroid cancers have an aggressive prognosis. So, identifying the risk factors for poor prognosis in thyroid cancer before surgery are very important.

In several studies, papillary thyroid microcarcinomas (i.e., papillary thyroid carcinomas measuring $\leq 10 \mathrm{~mm}$ ) diagnosed using ultrasonography (US) guided fine-needle aspiration biopsy (FNAB) were not surgically treated immediately after diagnosis $[5,6]$. According to an observational study in Japan, nodules $3 \mathrm{~mm}$ in size or larger increased $6.4 \%$ after 5 years and $15.9 \%$ after 10 years. In another study, 22 of 300 patients $(7 \%)$ showed nodules $3 \mathrm{~mm}$ in size or larger increased during the follow-up period. In studies regarding the predictors of thyroid cancer growth, thyroid-stimulating hormone (TSH) and tumor progression were not significantly associated [7]. In another study, patients under the age of 40 years showed a high incidence of node size enlargement and metastasis [8].

In this study, we evaluated changes in the length and volume of thyroid cancer nodules identified using FNAB or surgery and compared the change in size between thyroid cancer and benign nodules. Additionally, we analyzed the risk factors associated with the growth of thyroid cancer. The initial mean age, gender, TSH levels, autoantibody presence, initial nodule size, tallerthan-wide shape, and microcalcification were considered as risk factors for rapid progression of thyroid cancer nodule. To accurately analyze the change in size, we calculated the nodule volumes. In previous studies, to compare the nodule size increase, only a single thyroid US section was used. We analyzed the association of high maximum standardized uptake value (SUV) and thyroid nodule growth in several patients who underwent preoperative $\left[{ }^{18} \mathrm{~F}\right]$ Fluoro-2-D-deoxyglucose (FDG) positron emission tomography (PET)/computed tomography (CT) scan.

\section{METHODS}

\section{Subjects}

\section{Cancer group}

The present study was conducted at Yeouido St. Mary's Hospital and Seoul St. Mary's Hospital in Seoul, Korea. Inclusion criteria for the thyroid cancer group were the following: thyroid nodules confirmed using FNAB or surgery; FNAB results classified according to the Bethesda system; thyroid nodules diagnosed using FNAB defined as cancer nodules if the result either Bethesda V (suspicious for malignancy) or Bethesda VI (malignant); the patients underwent thyroid US at least two times at more than 1-year intervals (range, 12.5 to 47.5 months) before surgery.

The cancer group was divided into the prospective and retrospective observational groups. Thirty-eight patients (41 nodules) in the prospective observational group received follow-up thyroid US after FNAB-based diagnosis. These were all Bethesda V (suspicious for malignancy) or Bethesda VI (malignant). The retrospective observational group included 75 patients (79 nodules) who were diagnosed based on FNAB or surgery; Sixty-eight nodules were confirmed as Bethesda V or VI based on FNAB. Eleven nodules were non-diagnostic/atypia of undetermined significance/follicular lesion of undetermined significance (AUS/FLUS) by FNAB and confirmed as papillary thyroid carcinoma later by surgery. A total of 113 patients and 120 nodules were enrolled in the present study (Fig. 1).

Among the enrolled subjects, 75 underwent thyroidectomy. All thyroid nodules were confirmed as papillary thyroid carcinoma after surgery. If lymph node metastasis was invisible on thyroid US, thyroid nodules were observed without surgical resection. A total of 31 patients underwent nonsurgical observation.

\section{Benign group}

The benign group prospectively included patients with benign thyroid nodules identified using FNAB who underwent thyroid US at least twice at more than 1-year intervals. Cystic or predominantly cystic nodules (cystic portion of thyroid nodule at initial US $>50 \%$ ) were excluded. The size of nodules was matched to compare with the nodules of the cancer group. A total of 116 patients (119 nodules) were included in this group.

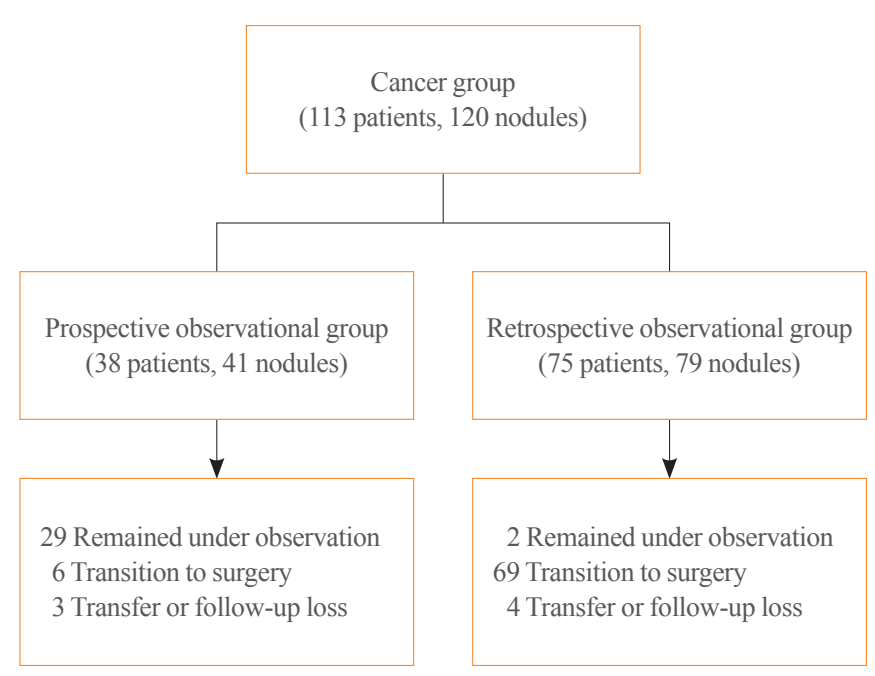

Fig. 1. Flow chart for cancer group enrollment. 


\section{Measurement and classification of variables}

Thyroid US was performed using 3000 or 5000 scanners (ATL, Philips, Bothell, WA, USA) with a 5 to $14 \mathrm{MHz}$ transducer. Thyroid US was performed by radiologist or endocrinologist in our institution and was reviewed and confirmed by one of our researchers (K.J.Y.). Depth and width were measured from the transverse view and length from the longitudinal view. The volume of the nodule was calculated using the formula for rotational ellipsoid; depth $(\mathrm{cm}) \times$ width $(\mathrm{cm}) \times$ length $(\mathrm{cm}) \times \pi / 6$ [9]. The nodule maximum diameter was defined as the longest diameter of the three measurements (depth, width, length). Taller than wide was defined as an anteroposterior/transverse diameter (A/T) ratio $>1$ in the transverse view, and $\mathrm{A} / \mathrm{T}$ ratio was also calculated. Calcification was considered as the presence of microcalcification. Cohen' $\kappa$ value was calculated to confirm the interobserver variability. The serum TSH (Beckman Coulter, Brea, CA, USA; normal range, 0.55 to $4.78 \mu \mathrm{IU} / \mathrm{mL}$ ), thyroid peroxidase antibody (TPO Ab; Roche Diagnostics, Rotkreuz, Switzerland; normal range, 0 to $34 \mathrm{U} / \mathrm{mL}$ ), and thyroglobulin antibody (Tg Ab; ZenTech, Angleur, Belgium; normal range, 0 to $115 \mathrm{U} / \mathrm{mL}$ ) were measured using chemiluminescent immunoassays.

Before surgery, 43 patients received a ${ }^{18} \mathrm{~F}$-FDG PET/CT. Two experienced nuclear medicine physicians reviewed the ${ }^{18} \mathrm{~F}-\mathrm{FDG}$ $\mathrm{PET} / \mathrm{CT}$. The maximum SUV was calculated in a region of interest. This study was approved by the Institutional Review Board of Yeouido St. Mary's Hospital (SC15RISI0047), and all patients signed informed consents before entering the study.

\section{Statistical analysis}

All data processing was performed with SPSS software version 18.0 software (SPSS Inc., Chicago, IL, USA). $t$ test and chisquare test were used to compare the baseline clinical characteristics and thyroid nodule change in the cancer and benign groups. The data were presented as mean \pm standard deviation for continuous variables and as proportions for categorical variables. Multiple linear regression analysis was performed to confirm progression risk factors for thyroid cancer nodules. The initial mean age, gender, TSH levels, autoantibody presence, initial maximum diameter, initial volume, depth/width ratio, and microcalcification were included as risk factors. The initial maximum diameter and initial volume were analyzed separately because of multicollinearity. To identify the relationships between pathologic findings and rapid progression of thyroid cancer nodules, the chi-square test was used. A $P<0.05$ was considered to indicate statistical significance.

\section{RESULTS}

The clinical baseline characteristics of the study population are presented in Table 1. The initial mean age, gender, TSH levels, TPO Ab levels, Tg Ab levels, number of FNABs, initial maximum diameter, and initial volume did not differ between the two groups. The taller than wide, $\mathrm{A} / \mathrm{T}$ ratio, and microcalcification finding on thyroid US appeared more frequently in the cancer group. FNAB results in the cancer group were nondiagnostic or unsatisfactory or AUS/FLUS (11.8\%), suspicious for malignancy (33.3\%), and malignancy (51.0\%).

The mean follow-up durations in the cancer group and the benign group were $29.5 \pm 18.8$ months (range, 12 to 94 ) and $31.9 \pm$ 15.8 months (range, 12 to 85$)$, respectively $(P=0.32)$ (Table 2 ).

\begin{tabular}{|c|c|c|c|}
\hline Characteristic & $\begin{array}{c}\text { Cancer group } \\
(n=113,120 \\
\text { nodules })\end{array}$ & $\begin{array}{c}\text { Benign group } \\
(n=116,119 \\
\text { nodules })\end{array}$ & $P$ value \\
\hline Age, yr & $48.8 \pm 11.5$ & $51.0 \pm 10.4$ & 0.13 \\
\hline Female sex & $97(85.8)$ & $98(84.5)$ & 0.67 \\
\hline $\mathrm{TSH}, \mu \mathrm{IU} / \mathrm{mL}$ & $2.4 \pm 2.4$ & $2.1 \pm 2.5$ & 0.47 \\
\hline Autoantibody (positive) & $33(29.2)$ & $18(15.5)$ & 0.21 \\
\hline ТРО Ab & $59.9 \pm 132.9$ & $91.3 \pm 329.0$ & 0.42 \\
\hline $\operatorname{Tg} \mathrm{Ab}$ & $134.2 \pm 434.7$ & $102.0 \pm 278.0$ & 0.58 \\
\hline No. of FNABs & $1.6 \pm 0.9$ & $1.4 \pm 0.7$ & 0.05 \\
\hline $\begin{array}{l}\text { Initial maximum diameter, } \\
\mathrm{mm}\end{array}$ & $7.4 \pm 3.9$ & $8.2 \pm 2.6$ & 0.05 \\
\hline Initial volume, $\mathrm{mL}$ & $0.27 \pm 0.69$ & $0.19 \pm 0.16$ & 0.21 \\
\hline Taller than wide & $47(39.2)$ & $11(9.2)$ & $<0.01$ \\
\hline $\mathrm{A} / \mathrm{T}$ ratio & $1.00 \pm 0.34$ & $0.73 \pm 0.19$ & $<0.01$ \\
\hline Microcalcification & $50(41.7)$ & $12(10.1)$ & $<0.01$ \\
\hline \multicolumn{4}{|l|}{ Initial FNAB results } \\
\hline Benign & 0 & $119(100)$ & \\
\hline $\begin{array}{l}\text { Nondiagnostic or unsatis- } \\
\text { factory or AUS/FLUS }\end{array}$ & $11(9.2)$ & & \\
\hline Suspicious for malignancy & $46(38.3)$ & & \\
\hline Malignancy & $63(52.5)$ & & \\
\hline
\end{tabular}

Values are expressed as mean \pm SD or number (\%).

$\mathrm{TSH}$, thyroid stimulating hormone; TPO Ab, thyroid peroxidase antibody; $\mathrm{Tg} \mathrm{Ab}$, thyroglobulin antibody; FNAB, fine-needle aspiration biopsy; A/T ratio, anteroposterior/transverse diameter ratio in the transverse view; AUS/FLUS, Atypia of Undetermined Significance/Follicular Lesion of Undetermined Significance.

${ }^{a}$ It is the result of FNAB before surgery. AUS/FLUS in cancer group were histologically confirmed as classic papillary thyroid carcinoma by surgery. 
We calculated maximum diameter change $(\mathrm{mm}) /$ year, volume change $(\mathrm{mL}) /$ year and volume change (\%)/year for adjusting duration. The maximum diameter change $(\mathrm{mm})$ /year was $0.36 \pm$ $0.97 \mathrm{~mm}$ in the cancer group and $-0.04 \pm 0.77 \mathrm{~mm}$ in the benign group $(P<0.01)$. Additionally, the volume change $(\mathrm{mL}) /$ year and volume change $(\%) /$ year were significantly increased in the

Table 2. Changes in the Thyroid Nodules on Thyroid Ultrasound

\begin{tabular}{|c|c|c|c|}
\hline Variable & $\begin{array}{l}\text { Cancer group } \\
\quad(n=113, \\
120 \text { nodules })\end{array}$ & $\begin{array}{c}\text { Benign group } \\
\quad(n=116, \\
119 \text { nodules })\end{array}$ & $P$ value \\
\hline Follow-up duration, mo & $29.5 \pm 18.8$ & $31.9 \pm 15.8$ & 0.32 \\
\hline $\begin{array}{l}\text { Total maximum diameter } \\
\text { change, } \mathrm{mm}\end{array}$ & $0.82 \pm 2.03$ & $0.10 \pm 1.72$ & $<0.01$ \\
\hline Total volume change, $\mathrm{mL}$ & $0.17 \pm 0.57$ & $0.03 \pm 0.15$ & $<0.01$ \\
\hline Total volume change, $\%$ & $70.3 \pm 219.2$ & $15.4 \pm 84.2$ & 0.01 \\
\hline $\begin{array}{l}\text { Maximum diameter change, } \\
\mathrm{mm} / \mathrm{yr}\end{array}$ & $0.36 \pm 0.97$ & $-0.04 \pm 0.77$ & $<0.01$ \\
\hline Volume change, $\mathrm{mL} / \mathrm{yr}$ & $0.06 \pm 0.18$ & $0.004 \pm 0.05$ & $<0.01$ \\
\hline Volume change, $\% / \mathrm{yr}$ & $26.9 \pm 57.9$ & $1.7 \pm 26.0$ & $<0.01$ \\
\hline Maximal diameter change & & & 0.04 \\
\hline$<3 \mathrm{~mm}$ change & $112(93.3)$ & $108(90.8)$ & \\
\hline$\geq 3 \mathrm{~mm}$ increase & $8(6.7)$ & $5(4.2)$ & \\
\hline$\geq 3 \mathrm{~mm}$ decrease & 0 & $6(5.0)$ & \\
\hline Volume change & & & $<0.01$ \\
\hline$<30 \%$ change & $60(50.0)$ & $75(63.0)$ & \\
\hline $30 \%-50 \%$ increase & $17(14.2)$ & $10(8.4)$ & \\
\hline$\geq 50 \%$ increase & $38(31.7)$ & $16(13.5)$ & \\
\hline$\geq 30 \%$ decrease & $5(4.1)$ & $18(15.1)$ & \\
\hline
\end{tabular}

cancer group compared with the benign group. The volume change (\%)/year were $26.9 \% \pm 57.9 \%$ in the cancer group and $1.7 \% \pm 26.0 \%$ in the benign group $(P<0.01)$. The initial nodule volume increased $50 \%$ or more during follow-up in $31.7 \%$ of the cancer group patients and $13.5 \%$ of the benign group patients. The patients in the prospective observational group underwent thyroid US every 6 or 12 months. New lymph node metastasis in the left level VI was found only in one patient whose FNAB results of suspicious lymph node included a few clusters of atypical cells, suspicious of metastatic carcinoma. The patient underwent total thyroidectomy with dissection of both central lymph nodes.

Multiple linear regression analysis was performed to determine the risk factors of rapid progression of thyroid cancer nodules (Table 3). The initial age, gender, TSH levels, thyroid autoantibody levels, and microcalcification were not associated with volume change $(\mathrm{mL}) /$ year and volume change $(\%) /$ year. However, initial maximum diameter $(\beta=0.02, P<0.01)$ and initial volume $(\beta=0.13, P<0.01)$ were significantly associated with volume change $(\mathrm{mL}) /$ year. The pathologic findings were confirmed in 75 patients after surgery. To verify the relevance of the thyroid cancer nodule growth and pathologic findings, the patients were divided into two groups based on the presence of microscopic extrathyroid extension (ETE) or lymph node metastasis (Table 4). However, microscopic ETE and lymph node metastasis were not associated with tumor volume growth.

We performed subgroup analyses of the 43 patients who received preoperative ${ }^{18} \mathrm{~F}$-FDG PET/CT. The total maximum SUV average was $3.51 \pm 2.91$. The maximum SUVs were not associated with volume change $(\mathrm{mL}) /$ year and volume change $(\%) / y e a r$ after adjusting for initial mean age, gender, TSH lev-

Table 3. Risk Factors for Progression of Thyroid Cancer Nodules in Multiple Linear Regression Analysis

\begin{tabular}{|c|c|c|c|c|c|c|}
\hline \multirow{2}{*}{ Variable } & \multicolumn{2}{|c|}{ Maximum diameter change, $\mathrm{mm} / \mathrm{yr}$} & \multicolumn{2}{|c|}{ Volume change, $\mathrm{mL} / \mathrm{yr}$} & \multicolumn{2}{|c|}{ Volume change, $\% / \mathrm{yr}$} \\
\hline & $\beta$ & $P$ value & $\beta$ & $P$ value & $\beta$ & $P$ value \\
\hline Age, yr & 0.11 & 0.25 & 0.00 & 0.61 & 0.40 & 0.42 \\
\hline Female sex & -0.02 & 0.84 & -0.02 & 0.57 & -19.70 & 0.20 \\
\hline $\mathrm{TSH}, \mu \mathrm{IU} / \mathrm{mL}$ & -0.07 & 0.44 & -0.002 & 0.58 & -2.74 & 0.27 \\
\hline Autoantibody (positive) & 0.00 & 0.98 & -0.01 & 0.56 & 22.40 & 0.08 \\
\hline Initial maximum diameter, $\mathrm{mm}$ & 0.35 & $<0.01$ & 0.02 & $<0.01$ & 3.63 & 0.21 \\
\hline Initial volume, $\mathrm{mL}$ & 0.12 & 0.43 & 0.13 & $<0.01$ & -2.22 & 0.78 \\
\hline $\mathrm{A} / \mathrm{T}$ ratio & 0.03 & 0.73 & 0.03 & 0.35 & 26.00 & 0.14 \\
\hline Microcalcification & -0.03 & 0.75 & -0.05 & 0.05 & -16.90 & 0.19 \\
\hline
\end{tabular}


Table 4. Relationship of Pathologic Finding and Rapid Progression of Thyroid Cancer Nodules

\begin{tabular}{|c|c|c|c|c|c|c|}
\hline \multirow{2}{*}{ Variable } & \multicolumn{3}{|c|}{ Microscopic extrathyroid extension } & \multicolumn{3}{|c|}{ Lymph node metastasis } \\
\hline & $\mathrm{N}(n=46)$ & $\mathrm{Y}(n=29)$ & $P$ value & $\mathrm{N}(n=46)$ & $\mathrm{Y}(n=25)$ & $P$ value \\
\hline Maximum diameter change, $\mathrm{mm} / \mathrm{yr}$ & $0.29 \pm 0.64$ & $0.39 \pm 0.59$ & 0.46 & $0.33 \pm 0.72$ & $0.25 \pm 0.34$ & 0.60 \\
\hline Volume change, $\mathrm{mL} / \mathrm{yr}$ & $0.04 \pm 0.12$ & $0.10 \pm 0.19$ & 0.12 & $0.06 \pm 0.14$ & $0.06 \pm 0.18$ & 0.94 \\
\hline Volume change, $\% / \mathrm{yr}$ & $27.3 \pm 75.1$ & $21.0 \pm 26.5$ & 0.67 & $28.1 \pm 75.4$ & $17.6 \pm 23.8$ & 0.50 \\
\hline
\end{tabular}

Values are expressed as mean \pm SD.

$\mathrm{N}$, not present; Y, present.

Table 5. Subgroup Analysis of Risk Factors for Progression of Thyroid Cancer Nodules in Patients Who Underwent Preoperative ${ }^{18} \mathrm{~F}-$ FDG PET/CT $(n=43)$

\begin{tabular}{|c|c|c|c|c|c|c|}
\hline \multirow{2}{*}{ Variable } & \multicolumn{2}{|c|}{ Maximum diameter change, $\mathrm{mm} / \mathrm{yr}$} & \multicolumn{2}{|c|}{ Volume change, $\mathrm{mL} / \mathrm{yr}$} & \multicolumn{2}{|c|}{ Volume change, $\% / y r$} \\
\hline & $\beta$ & $P$ value & $\beta$ & $P$ value & $\beta$ & $P$ value \\
\hline Age, yr & 0.00 & 0.99 & 0.001 & 0.40 & 1.41 & 0.21 \\
\hline Female sex & 0.17 & 0.27 & -0.02 & 0.65 & -25.60 & 0.51 \\
\hline $\mathrm{TSH}, \mu \mathrm{IU} / \mathrm{mL}$ & 0.00 & 0.98 & 0.01 & 0.58 & -5.33 & 0.62 \\
\hline Autoantibody (positive) & 0.06 & 0.68 & 0.002 & 0.96 & 35.60 & 0.25 \\
\hline Initial maximum diameter, $\mathrm{mm}$ & 0.83 & 0.16 & 0.04 & 0.61 & 0.72 & 0.85 \\
\hline Initial volume, $\mathrm{mL}$ & 0.57 & $<0.01$ & 0.27 & 0.35 & -2.36 & 0.94 \\
\hline $\mathrm{A} / \mathrm{T}$ ratio & 0.10 & 0.53 & 0.02 & 0.78 & 21.90 & 0.64 \\
\hline Microcalcification & -0.08 & 0.64 & -0.04 & 0.32 & -12.40 & 0.67 \\
\hline Maximum SUV & 0.70 & 0.84 & 0.00 & 0.98 & 2.38 & 0.67 \\
\hline
\end{tabular}

${ }^{18} \mathrm{~F}-\mathrm{FDG},\left[{ }^{18} \mathrm{~F}\right]$ fluoro-2-D-deoxyglucose; PET, positron emission tomography; CT, computed tomography; TSH, thyroid stimulating hormone; A/T ratio, anteroposterior/transverse diameter ratio in the transverse view; SUV, standardized uptake value.

els, thyroid autoantibody presence, initial maximum diameter, initial volume, depth/width ratio, and microcalcification in the multiple linear regression analysis (Table 5). Additionally, the maximum SUV depending on the presence or absence of lymph node metastasis and microscopic ETE was not significantly different (data not shown).

\section{DISCUSSION}

According to the American Thyroid Association guideline [10], significant thyroid nodule size change was defined as more than $50 \%$ volume increase or $2 \mathrm{~mm}$ and $20 \%$ nodule diameter increase in at least two nodule dimensions. In the present study, we compared the size change of cancer nodules and benign nodules during an average follow-up of $30.1 \pm 17.1$ months. The maximum diameter change/year was $0.36 \pm 0.97 \mathrm{~mm}$ in the cancer group and $-0.04 \pm 0.77 \mathrm{~mm}$ in the benign group $(P<0.01)$. In addition, volume change $(\%) / y e a r$ was significantly increased in the cancer group compared with the benign group $(26.9 \% \pm$ $57.9 \%$ vs. $1.7 \% \pm 26.0 \%, P<0.01)$. Initial maximum diameter and initial volume were independent risk factors for cancer nodule growth in the multiple regression analysis. However, there was no association between cancer nodule growth and pathologic findings.

In the present study, the annual maximum diameter change in the cancer nodules was approximately only $0.36 \mathrm{~mm}$. However, the annual volume change showed a significant increase of approximately $27 \%$. The nodule diameter observed on thyroid US single plane may vary depending on the examiner's skill or angle in the thyroid US plane. Therefore, evaluating the size change by comparing the length difference of the nodule in a single US section is difficult. Thyroid nodule growth was defined as 3-mm change in diameter in several observational studies $[5,6,11]$. However, measuring the volume of thyroid nodules to assess the size change would be more accurate. This finding is consistent with the previous studies [12-14]. 
Several studies regarding the volume change of benign thyroid nodules using thyroid US have been performed [15-18]. When using $50 \%$ as a cut-off value, $10 \%$ to $15 \%$ of thyroid nodules increased in volume after 20 months of follow-up. When using $30 \%$ as a cut-off value, $25 \%$ to $50 \%$ of thyroid nodules increased in volume after 40 to 60 months of follow-up. In the present study, when using $50 \%$ and $30 \%$ as cut-off values in the benign group, $13.5 \%$ and $15.1 \%$ of thyroid nodules increased in volume, respectively. These results were not significantly different from other studies. When using 50\% and 30\% as cut-off values in the cancer group, $31.7 \%$ and $4.1 \%$ of thyroid nodules increased in volume, respectively. These results show a two-fold difference between the two groups.

The risk factors for thyroid cancer nodule growth are still controversial. Recent studies showed that higher serum TSH is associated with a higher incidence of thyroid cancer, advanced stage thyroid cancer, and tumor growth during active surveillance [19-23]. Other studies showed thyroid autoimmunity such as positive $\mathrm{Tg} \mathrm{Ab}$ is a risk factor for thyroid cancer [20,24]. However, in prospective cohort studies in Japan, size progression of thyroid cancer was not associated with TSH levels and thyroid autoimmunity [6,7]. Ito et al. [8] reported that youngeraged ( $<40$ years) patients exhibited more rapid progression of thyroid cancer and node metastasis. Recently, Oh et al. [12] also reported active surveillance should be carefully applied for younger patients. According to our results, age, gender, TSH levels, and thyroid autoantibody were not associated with thyroid cancer nodule growth. Initial size was an independent risk factor for cancer nodule growth. Several studies reported that initial tumor size had no effect on thyroid cancer progression $[6,7]$. However, in the present study the initial tumor volume was included and adjusted for several related risk factors. This is consistent with the recently published study by Oh et al. [12]. Further high-quality prospective studies regarding initial tumor size and progression are needed.

${ }^{18} \mathrm{~F}$-FDG PET/CT is an imaging tool using the characteristics of increased glucose metabolism in cancer cells [25]. FDG uptake in ${ }^{18} \mathrm{~F}$-FDG PET/CT is a useful predictor for prognosis and metastasis in many malignant tumors [26-28]. Several published studies showed ${ }^{18} \mathrm{~F}-\mathrm{FDG} \mathrm{PET} / \mathrm{CT}$ were effective for the prediction of recurrence and prognosis after thyroidectomy [29,30]. However, whether FDG positivity in primary thyroid cancer is effective for predicting prognosis remains unknown. In several studies, the FDG positive group showed a higher prevalence of microscopic ETE and central lymph node involvement compared with the FDG negative group [31,32]. In contrast, other studies reported that preoperative FDG uptake in thyroid cancer was not associated with postoperative pathology [33,34]. We performed subgroup analyses in patients receiving preoperative ${ }^{18}$ F-FDG PET/CT. Maximum SUV values did not affect the nodule growth and were not associated with lymph node metastasis and microscopic ETE.

The present study had several strengths. First, we compared the nodule growth in both the cancer and benign groups. Additionally, the baseline characteristics between the two groups did not significantly differ. Second, several risk factors including maximum SUV values for thyroid cancer nodule growth were analyzed. However, the present study had several limitations. First, the sample size was small. Second, thyroid nodules belonging to the inclusion criteria were selected; therefore, a selection bias may have existed. Third, benign nodules and some cancer nodules were diagnosed with non-surgical, FNAB. However, FNAB is a highly accurate diagnostic method. Several studies reported that the sensitivity and specificity levels of FNAB were $80 \%$ to $90 \%$ and $94 \%$ to $98 \%$, respectively [35-37]. Fourth, the number of FNABs performed could have affected the change in nodule size. However, the numbers of FNABs performed in the two groups were similar. Additionally, predominantly cystic or cystic nodules were excluded in the benign group because the nodule size may be susceptible to FNABs. Finally, this study included relatively small thyroid nodules, which caused concern about the biased measurement. In conclusion, the thyroid cancer nodules showed rapid progression compared with benign nodules. The initial maximum diameter and initial volume were independent risk factors for cancer nodule growth.

\section{CONFLICTS OF INTEREST}

No potential conflict of interest relevant to this article was reported.

\section{AUTHOR CONTRIBUTIONS}

Conception or design: K.J.Y., K.H.S., K.H.B. Acquisition, analysis, or interpretation of data: K.J.Y., J.H., M.H.K., Y.Y.S., M.K.K. Drafting the work or revising: K.J.Y., J.H. Final approval of the manuscript: H.S.K., K.H.S., M.I.K., K.H.B.

\section{ORCID}

Kyun-Jin Yun https://orcid.org/0000-0002-4823-141X 
Jeonghoon Ha https://orcid.org/0000-0001-9219-7135

Ki-Hyun Baek https://orcid.org/0000-0002-4097-1077

\section{REFERENCES}

1. Jung KW, Won YJ, Kong HJ, Oh CM, Seo HG, Lee JS. Cancer statistics in Korea: incidence, mortality, survival and prevalence in 2010. Cancer Res Treat 2013;45:1-14.

2. Sampson RJ, Woolner LB, Bahn RC, Kurland LT. Occult thyroid carcinoma in Olmsted County, Minnesota: prevalence at autopsy compared with that in Hiroshima and Nagasaki, Japan. Cancer 1974;34:2072-6.

3. Sampson RJ, Key CR, Buncher CR, Iijima S. Thyroid carcinoma in Hiroshima and Nagasaki. I. Prevalence of thyroid carcinoma at autopsy. JAMA 1969;209:65-70.

4. Bondeson L, Ljungberg O. Occult thyroid carcinoma at autopsy in Malmo, Sweden. Cancer 1981;47:319-23.

5. Sugitani I, Toda K, Yamada K, Yamamoto N, Ikenaga M, Fujimoto Y. Three distinctly different kinds of papillary thyroid microcarcinoma should be recognized: our treatment strategies and outcomes. World J Surg 2010;34:1222-31.

6. Ito Y, Miyauchi A, Inoue H, Fukushima M, Kihara M, Higashiyama $\mathrm{T}$, et al. An observational trial for papillary thyroid microcarcinoma in Japanese patients. World J Surg 2010;34:28-35.

7. Sugitani I, Fujimoto Y, Yamada K. Association between serum thyrotropin concentration and growth of asymptomatic papillary thyroid microcarcinoma. World J Surg 2014;38: 673-8.

8. Ito Y, Miyauchi A, Kihara M, Higashiyama T, Kobayashi K, Miya A. Patient age is significantly related to the progression of papillary microcarcinoma of the thyroid under observation. Thyroid 2014;24:27-34.

9. Knudsen N, Bols B, Bulow I, Jorgensen T, Perrild H, Ovesen $\mathrm{L}$, et al. Validation of ultrasonography of the thyroid gland for epidemiological purposes. Thyroid 1999;9:106974.

10. American Thyroid Association (ATA) Guidelines Taskforce on Thyroid Nodules and Differentiated Thyroid Cancer, Cooper DS, Doherty GM, Haugen BR, Kloos RT, Lee SL, et al. Revised American Thyroid Association management guidelines for patients with thyroid nodules and differentiated thyroid cancer. Thyroid 2009;19:1167-214.

11. Ito Y, Miyauchi A. A therapeutic strategy for incidentally detected papillary microcarcinoma of the thyroid. Nat Clin Pract Endocrinol Metab 2007;3:240-8.
12. Oh HS, Ha J, Kim HI, Kim TH, Kim WG, Lim DJ, et al. Active surveillance of low-risk papillary thyroid microcarcinoma: a multi-center cohort study in Korea. Thyroid 2018;28: 1587-94.

13. Kwon H, Oh HS, Kim M, Park S, Jeon MJ, Kim WG, et al. Active surveillance for patients with papillary thyroid microcarcinoma: a single center's experience in Korea. J Clin Endocrinol Metab 2017;102:1917-25.

14. Tuttle RM, Fagin JA, Minkowitz G, Wong RJ, Roman B, Patel S, et al. Natural history and tumor volume kinetics of papillary thyroid cancers during active surveillance. JAMA Otolaryngol Head Neck Surg 2017;143:1015-20.

15. Quadbeck B, Pruellage J, Roggenbuck U, Hirche H, Janssen OE, Mann K, et al. Long-term follow-up of thyroid nodule growth. Exp Clin Endocrinol Diabetes 2002;110:348-54.

16. Lim DJ, Kim JY, Baek KH, Kim MK, Park WC, Lee JM, et al. Natural course of cytologically benign thyroid nodules: observation of ultrasonographic changes. Endocrinol Metab (Seoul) 2013;28:110-8.

17. Erdogan MF, Gursoy A, Erdogan G. Natural course of benign thyroid nodules in a moderately iodine-deficient area. Clin Endocrinol (Oxf) 2006;65:767-71.

18. Alexander EK, Hurwitz S, Heering JP, Benson CB, Frates MC, Doubilet PM, et al. Natural history of benign solid and cystic thyroid nodules. Ann Intern Med 2003;138:315-8.

19. McLeod DS, Watters KF, Carpenter AD, Ladenson PW, Cooper DS, Ding EL. Thyrotropin and thyroid cancer diagnosis: a systematic review and dose-response meta-analysis. J Clin Endocrinol Metab 2012;97:2682-92.

20. Kim ES, Lim DJ, Baek KH, Lee JM, Kim MK, Kwon HS, et al. Thyroglobulin antibody is associated with increased cancer risk in thyroid nodules. Thyroid 2010;20:885-91.

21. Haymart MR, Repplinger DJ, Leverson GE, Elson DF, Sippel RS, Jaume JC, et al. Higher serum thyroid stimulating hormone level in thyroid nodule patients is associated with greater risks of differentiated thyroid cancer and advanced tumor stage. J Clin Endocrinol Metab 2008;93:809-14.

22. Haymart MR, Glinberg SL, Liu J, Sippel RS, Jaume JC, Chen H. Higher serum TSH in thyroid cancer patients occurs independent of age and correlates with extrathyroidal extension. Clin Endocrinol (Oxf) 2009;71:434-9.

23. Kim HI, Jang HW, Ahn HS, Ahn S, Park SY, Oh YL, et al. High serum TSH level is associated with progression of papillary thyroid microcarcinoma during active surveillance. J Clin Endocrinol Metab 2018;103:446-51.

24. Vasileiadis I, Boutzios G, Charitoudis G, Koukoulioti E, 
Karatzas T. Thyroglobulin antibodies could be a potential predictive marker for papillary thyroid carcinoma. Ann Surg Oncol 2014;21:2725-32.

25. Buerkle A, Weber WA. Imaging of tumor glucose utilization with positron emission tomography. Cancer Metastasis Rev 2008;27:545-54.

26. Vansteenkiste J, Fischer BM, Dooms C, Mortensen J. Positron-emission tomography in prognostic and therapeutic assessment of lung cancer: systematic review. Lancet Oncol 2004;5:531-40.

27. Kidd EA, Siegel BA, Dehdashti F, Grigsby PW. The standardized uptake value for F-18 fluorodeoxyglucose is a sensitive predictive biomarker for cervical cancer treatment response and survival. Cancer 2007;110:1738-44.

28. Eubank WB, Mankoff DA. Evolving role of positron emission tomography in breast cancer imaging. Semin Nucl Med 2005;35:84-99.

29. Wang W, Larson SM, Fazzari M, Tickoo SK, Kolbert K, Sgouros G, et al. Prognostic value of [18F]fluorodeoxyglucose positron emission tomographic scanning in patients with thyroid cancer. J Clin Endocrinol Metab 2000;85:110713.

30. Feine U, Lietzenmayer R, Hanke JP, Held J, Wohrle H, Muller-Schauenburg W. Fluorine-18-FDG and iodine-131iodide uptake in thyroid cancer. J Nucl Med 1996;37:146872.

31. Yun M, Noh TW, Cho A, Choi YJ, Hong SW, Park CS, et al.
Visually discernible [18F]fluorodeoxyglucose uptake in papillary thyroid microcarcinoma: a potential new risk factor. J Clin Endocrinol Metab 2010;95:3182-8.

32. Mitchell JC, Grant F, Evenson AR, Parker JA, Hasselgren PO, Parangi S. Preoperative evaluation of thyroid nodules with 18FDG-PET/CT. Surgery 2005;138:1166-74.

33. Kim MH, Ko SH, Bae JS, Lee SH, Jung CK, Lim DJ, et al. Non-FDG-avid primary papillary thyroid carcinoma may not differ from FDG-avid papillary thyroid carcinoma. Thyroid 2013;23:1452-60.

34. Jeong HS, Chung M, Baek CH, Ko YH, Choi JY, Son YI. Can [18F]-fluorodeoxyglucose standardized uptake values of PET imaging predict pathologic extrathyroid invasion of thyroid papillary microcarcinomas? Laryngoscope 2006;116: 2133-7.

35. Sinna EA, Ezzat N. Diagnostic accuracy of fine needle aspiration cytology in thyroid lesions. J Egypt Natl Canc Inst 2012;24:63-70.

36. Ko HM, Jhu IK, Yang SH, Lee JH, Nam JH, Juhng SW, et al. Clinicopathologic analysis of fine needle aspiration cytology of the thyroid. A review of 1,613 cases and correlation with histopathologic diagnoses. Acta Cytol 2003;47: 727-32.

37. Amrikachi M, Ramzy I, Rubenfeld S, Wheeler TM. Accuracy of fine-needle aspiration of thyroid. Arch Pathol Lab Med 2001;125:484-8. 